M. Д. Иванова. Экологический учет как составляющая экологической безопасности субъекта

Научная статья

УДК 657:574

DOI: $10.18101 / 2304-4446-2021-2-19-23$

\title{
ЭКОЛОГИЧЕСКИЙ УЧЕТ КАК СОСТАВЛЯЮЩАЯ ЭКОЛОГИЧЕСКОЙ БЕЗОПАСНОСТИ СУБЪЕКТА
}

\author{
(C) Иванова Маргарита Дашищыреновна \\ кандидат экономических наук, доцент, \\ Бурятский государственный университет имени Доржи Банзарова \\ Россия, 670000, г. Улан-Удэ, ул. Смолина, 24а \\ btipb@mail.ru
}

\begin{abstract}
Аннотация. В статье раскрыты признаки различных подсистем бухгалтерского учета, определена краткая их сравнительная характеристика. Отдельное внимание уделено экологическому учету, необходимости его выделения как составляющей экологической безопасности предприятий. Определены цель, задачи, функции, объекты и пользователи экологического учета. Рассмотрено, как субъекты более полно получат информацию о природоохранной деятельности, затратах на природоохранные мероприятия из экологического учета. Формирование экологической отчетности основывается на выделении в бухгалтерском учете природоохранных затрат и организации экологического учета, позволяет с учетом экологических показателей справедливо определить финансовое состояние предприятий.

Ключевые слова: бухгалтерский учет, финансовый учет, управленческий учет, налоговый учет, экологический учет, объекты учета, нормативное регулирование, природоохранная деятельность, природоохранные мероприятия
\end{abstract}

\section{Для цитирования}

Иванова М. Д. Экологический учет как составляющая экологической безопасности субъекта // Вестник Бурятского государственного университета. Экономика и менеджмент. 2021. № 2. С. 19-23.

Бухгалтерский учет включает подсистемы финансового, управленческого и налогового учета, в каждой подсистеме можно выделить экологический учет. Либо выделяется самостоятельная система учета - экологическая, соответственно, имеющая цели, задачи, функции. Надо отметить, что до сих пор нет определения сущности и содержания экологического учета заключающегося в рассмотрении особенностей учета в сфере охраны природопользования. Экологический учет формирует экологическую информацию и будет считаться подсистемой учета [1]. Это будет самостоятельной системой, отражающей применение природных ресурсов, определение стоимостной оценки, позволяющей показать влияние хозяйствующего субъекта на природную среду. Одновременно позволит выделить отдельно величину мероприятий, направленных на охрану природы [3].

В экологическом учете объектами являются факты деятельности организации, связанной с охраной природы, с применением природных ресурсов.

Природоохранная деятельность отражается только в экологическом учете, в то время в целом по предприятию ведется финансовый учет, который рассматривает его как целостный хозяйствующий организм. Управленческий учет ведется 
по местам возникновения затрат, сегментам рынка, центрам ответственности, по предприятию обобщается в целом.

Исходя из этого, следует, экологический учет - это процесс наблюдения, отражения природоохранных затрат, природных активов, экологических фондов, резервов, и обязательств, а также результатов деятельности хозяйствующих субъектов с целью управления и определения экологического потенциала организации [5].

Содержание, периодичность и сроки представления отчетности различны для всех рассмотренных систем учета. Создание теоретической модели учета экологической информации необходимо для формирования учетной информации, позволяющей исследовать в системе бухгалтерского учета взаимосвязь экологического, управленческого, финансового учета.

Экологический учет организации ведут в соответствии с действующими правилами финансового учета. Предприятие представляет собой совокупность фактов хозяйственной деятельности, находящих отражение в учете [3]. Показатели, характеризующие природоохранные действия, отражаются в первичных документах, группируются и обобщаются во всех подсистемах учета, в частности в финансовом, используются при прогнозировании, планировании, контроле, в анализе хозяйственной деятельности. Для разработки управленческих решений информация является основой, оказывает влияние на управление - появляется новое качество, новый информационный поток. Надо отметить, что экологический учет на микроуровне представляет собой отдельную подсистему бухгалтерского учета, включающую полный сбор информации, денежное измерение, систематизацию информации об экологических фактах, возникающих при осуществлении природоохранных мероприятий хозяйствующего субъекта.

Определенные приоритеты экологического учета вытекают из интересов потребителей информации. Особенной чертой при организации экологического учета является его направленность, оперативность, при которой приоритет отдается внутренним потребностям.

Основной функцией экологического учета является управление, экологическое планирование и контрольная. Цели и задачи экологического учета соизмеримы и соответствуют экологической политике субъекта. Экологическая программа включает цели и задачи, перечень природоохранных мероприятий, планируемые экономические показатели, периоды выполнения задач.

Основополагающие принципы экологического учета можно сформулировать на основе анализа становления экологического учета. Российские предприятия планируют получение прибыли без учета экологических требований. Экологизация производства связана с выявлением потребителей, предпочитающих экологически чистую продукцию, со средозащитными мероприятиями. В деятельности предприятия управленческих инструментов, составной частью которых является экологический учет, который зависит от соблюдения природоохранных норм и требований. Следует подчеркнуть, что для введения экологического учета необходимо разработать и теоретически обосновать методологию, правила экологического учета.

Основной задачей экологического учета будет разработка системы управления предприятием, объединяющей в себе различные элементы:

- определение цели; 
M. Д. Иванова. Экологический учет как составляющая экологической безопасности субъекта

- формирование информации, контроль;

- планирование;

- управление информацией;

- рассмотрение рекомендаций для управленческих решений в области экологии [6].

В работах отечественных авторов недостаточно освещены вопросы организации учета природоохранных затрат и обязательств, отсутствуют правила организации учета выбросов, сбросов, отходов [4].

Организуя экологический учет, следует определить три взаимосвязанных составляющих: информационное обеспечение, цель, задача. При помощи научных методов, правил и принципов бухгалтерского учета достигается информационное обеспечение экологоориентированного учета. На определенной организационно-методической основе, включающей множество элементов, возникают вопросы организации экологического учета, которые образуют целостность единства учета.

При использовании данной технологии необходимо разработать методические основы по организации направления бухгалтерского учета - экологического учета.

По мере организации экологического учета возникает необходимость создания системы учета, включающей экологическую составляющую, позволяющей представить систему экологически дифференцированного учета. В связи с этим интеграция учета природоохранной деятельности в существующую систему бухгалтерского учета предприятия будет сложной проблемой по следующим причинам:

во-первых, в бухгалтерском учете денежное измерение является основным показателем ${ }^{1}$, к некоторым природоохранным мероприятиям невозможно применение денежного эквивалента. При этом надо напомнить, что не являются объектом бухгалтерского учета средства, для которых невозможно применить денежную оценку. Компоненты природной среды оцениваются в натуральных измерителях и в бухгалтерском учете отсутствуют. В денежном измерении пока не существует методики отражения этих показателей. Если ресурс являлся активом, контролируемым предприятием, необходимо отразить эту информацию в учете;

- во-вторых в отражении в учете экологических аспектов деятельности организации должны быть заинтересованы. К бесконтрольному загрязнению природной среды ведет отсутствие такого учета на предприятиях. Относительно финансовых операций, предопределенных окружающей средой, а также экологические влияния на предприятия в учете природоохранной деятельности применяют способы и методы для анализа, отражения и отчетности. В экологическом учете основными объектами являются затраты на природоохранные мероприятия, информация о которых отражается в отчете о финансовых результатах деятельности, бухгалтерском балансе [4]. К природоохранным затратам, вызванным охраной окружающей среды, например, относятся штрафы за незаконные выбросы загрязняющих веществ, средства, направленные на улучшение состояния окружающей среды. По нашему мнению, система экологического учета на предприятии должна включать в себя три основные составляющие:

${ }^{1}$ О бухгалтерском учете: федеральный закон от 6 декабря 2011 г. № 402-Ф3. 
- экологический аудит;

- учет экологических расходов, обязательств;

- экологическая отчетность.

Расширение границ экологического учета даст возможность предприятиям более полно и объективно учитывать различные аспекты природоохранной деятельности и, в частности, степень влияния на окружающую среду. Организации в результате этого своевременно выявят риск возникновения чрезмерного вредного влияния на окружающую среду и примут необходимые меры, определяя, таким образом, экологичность производства предприятия ${ }^{1}$.

Специфичные требования введения экологического учета отличны от требований к информации для финансового учета. Информация экологического учета должна быть:

- оперативной;

- достаточной;

- целенаправленной;

- экономичной.

Введение экологического учета хозяйствующего субъекта основывается на нормативной базе:

- российского природопользования по его направлениям в области охраны окружающей среды;

- системы бухгалтерского учета.

Хозяйствующие субъекты являются частью природы ${ }^{2}$. Настоящее обстоятельство требует объективной необходимости достаточно полного отражения природоохранной деятельности в системе бухгалтерского учета с целью эффективного управления использования природных ресурсов.

Экологически сбалансированное развитие системы раскрывает принципы их взаимодействия и связывает три подсистемы: экономическую, экологическую и социальную. Структура информационных потоков, являющихся результатом взаимодействия двух подсистем: экономической и экологической, возникающих при функционировании этой системы, формирует модели оптимального развития экологической системы. Необходимо знать оценку качества природной среды, которое отражает уровень воздействия на среду и используется в системе экологического планирования. При повышении качества природной среды возникают дополнительные затраты, вызванные загрязнением окружающей природной среды, в результате которых улучшается состояние окружающей среды.

Таким образом, выделим, что в современной системе учета возникает необходимость выделения самостоятельной подсистемы - экологического учета как составляющей экологической безопасности субъекта.

\section{Литература}

1. Гоголева Т. Н., Бахтурина Ю. И. Экологический учет в системе видов учета // Международный бухгалтерский учет. 2015. № 3. С. 2-11. Текст: непосредственный.

2. Замула И. В., Липова А. Л. Бухгалтерский учет экологических обязательств потребителей // Международный бухгалтерский учет. 2014. № 22. С. 55-63. Текст: непосредственный.

\footnotetext{
${ }^{1}$ Об охране окружающей среды: федеральный закон от 10 января 2002 г. № 7-Ф3

${ }^{2}$ Там же.
} 
M. Д. Иванова. Экологический учет как составляющая экологической безопасности субъекта

3. Петрова Е. Е., Сисина Н. Н. Природоохранная деятельность предприятий: инвестирование, учет и анализ / Санкт-Петербургский государственный экономический университет. Санкт-Петербург, 2013. 199 с. Текст: непосредственный.

4. Морозова Е. В. Затраты на природоохранные мероприятия в системе финансового учета // Бухгалтерский учет. 2007. № 1. С. 74-76. Текст: непосредственный.

5. Саенко К. С. Инновационный и экологический учет: предпосылки и общие принципы их становления и развития // Аудит и финансовый анализ. 2007. № 5. С. 10-11. Текст: непосредственный.

6. Саенко К. С. Учет экологических затрат. Москва: Финансы и статистика. 2005. 206 с. Текст: непосредственный.

7. Титова С. Н. Составляем годовой отчет с помощью Минфина. Информация о природоохранных мероприятиях. URL: https://www.eg-online.ru/article/159803. Текст: электронный.

8. Санникова И. Н., Шавкунова Н. А. К вопросу о бухгалтерском экологическом учете и отчетности // Международный бухгалтерский учет. 2009. № 2. С. 2-7. Текст: непосредственный.

Статья поступила в редакиию 09.04.2021; одобрена после рецензирования 28.04.2021; принята к публикации 28.04.2021.

\section{ENVIRONMENTAL ACCOUNTING AS A COMPONENT OF ECOLOGICAL COMPLIANCE AT ENTERPRISES}

Margarita D. Ivanova

Cand. Sci. (Econ.), A/Prof.,

Dorzhi Banzarov Buryat State University

24a Smolina St., Ulan-Ude 670000, Russia

btipb@mail.ru

Abstract. The article analyzes the features of various accounting subsystems, gives their brief comparative characteristics. Special attention is paid to environmental accounting as a component of ecological compliance of enterprises. We have identified the purpose, tasks, functions, objects and users of environmental accounting. The article discusses how the subjects can fully obtain information on environmental protection activities, costs of environmental protection measures from environmental accounting. Environmental reporting is based on identification of environmental costs in accounting and organization of environmental accounting, and allows enterprises to determine their financial condition taking into account environmental indicators.

Keywords: accounting, financial accounting, management accounting, tax accounting, environmental accounting, objects of accounting, regulations, nature conservation activities, environmental protection measures

\section{For citation}

Ivanova M. D. Environmental Accounting as a Component of Ecological Compliance at Enterprises. Bulletin of Buryat State University. Economy and Management. 2021; 2: 19-23 (In Russ.)

The article was submitted 09.04.2021; approved after reviewing 28.04.2021; accepted for publication 28.04.2021. 